\title{
The Jiyuan tetrapod Fauna of the Upper Permian of China: New pareiasaur material and the reestablishment of Honania complicidentata
}

\author{
Li Xu, Xing-Wen Li, Song-Hai Jia, and Jun Liu \\ Acta Palaeontologica Polonica 60 (3), 2015: 689-700 doi:http://dx.doi.org/10.4202/app.00035.2013
}

Honania complicidentata and Tsiyuania simplicidentata are pareiasaur taxa based on material from the Shangshihezi Formation of Jiyuan, Henan Province, China that were earlier designated as nomina vana. Based on the study of new material, and the reexamination of old specimens, we determine that the pareiasaur material from Jiyuan represents a single species that differs from all known species from other localities. Thus, we resurrect the name $H$. complicidentata for the material from Jiyuan. $H$. complicidentata is characterized by maxillary teeth with high crowns, dentary teeth slightly posteriorly inclined compared to the dentary dorsal margin, nearly all preserved marginal teeth have a cusped cingulum on the lingual surface, and humerus without an ectepicondylar foramen. Phylogenetic analysis shows Honania is more basal than Shansisaurus and Shihtienfenia from the Sunjiagou Formation of China.

Key words: Reptilia, Pareiasauria, phylogeny, Permian, Shangshihezi Formation, China, Jiyuan.

Li Xu [xuli.312@163.com] and Song-Hai Jia [jiasonghai1962@qq.com], Henan Geological Museum, Zhenzhou, 450018, China; Xing-Wen Li [didalixingwen@163.com ] and Jun Liu [liujun@ivpp.ac.cn] (corresponding authors), Key Laboratory of Vertebrate Evolution and Human Origins of Chinese Academy of Sciences, Institute of Vertebrate Paleontology and Paleoanthropology, Chinese Academy of Sciences, Beijing, 100044, China.

This is an open-access article distributed under the terms of the Creative Commons Attribution License (for details please see creativecommons.org), which permits unrestricted use, distribution, and reproduction in any medium, provided the original author and source are credited. 
FaF 5 Full text $(982.7 \mathrm{kB})$

FoF Supplementary file $(75.2 \mathrm{kB})$ 